\title{
A percepção do pai frente ao nascimento do filho
}

\author{
The father's perception regarding the birth of his child
}

La percepción del padre sobre el nacimento de su hijo

Gabriela Fernanda lohann de Almeida ${ }^{1}$, Monique Eva Vargas Cardoso ${ }^{2 *}$, Rubellita Holanda Pinheiro Cunha Gois², Gisele Cassão².

\section{RESUMO}

Objetivo: Conhecer a percepção do pai frente ao nascimento do filho em uma maternidade pública de um Hospital do Rio Grande do Sul. Métodos: Estudo descritivo e qualitativo, realizado com pais durante o trabalho de parto e parto da sua companheira em um Alojamento Conjunto, utilizando entrevistas semiestruturadas para coleta de dados durante os meses de agosto e novembro de 2020. Resultados: Participaram do estudo 11 pais, com idade prevalente entre 20-30 anos, a maioria tem como grau de instrução ensino fundamental incompleto, a procedência de Parobé e o estado civil casado. O número de parto cesárea foi maior e $73 \%$ dos partos foram assistidos. Os achados do estudo propuseram refletir e discutir quanto a emoção e felicidade ao nascimento do filho, a satisfação com o atendimento da equipe, ansiedade e preocupação com o parto, expectativas com o nascimento, a participação durante o trabalho de parto e parto e a segurança em se tornar pai. Conclusão: Podemos evidenciar a importância e o desejo por parte dos pais em vivenciar estes momentos de forma ativa, ficando necessário incentivar os profissionais a promover a participação do acompanhante no momento de trabalho de parto e parto, inserindo-os e orientando-os quanto aos processos.

Palavras-chave: Enfermagem, Parto humanizado, Paternidade, Trabalho de parto.

\begin{abstract}
Objective: To know the father's perception regarding the birth of his child in a public maternity hospital in Rio Grande do Sul. Methods: A descriptive and qualitative study, carried out with fathers during labor and delivery of their partner in a Joint Lodging, using semi-structured interviews for data collection during the months of August and November 2020. Results: A total of 11 fathers participated in the study, with a prevalent age between 20-30 years old, most of them with incomplete elementary school education, coming from Parobé and married. The number of cesarean deliveries was higher and $73 \%$ of deliveries were assisted. The findings of the study proposed to reflect and discuss the emotion and happiness at the birth of the child, the satisfaction with the team's care, anxiety and concern with the birth, expectations with the birth, participation during labor and delivery, and safety in becoming a father. Conclusion: We can highlight the importance and the desire of parents to actively experience these moments, making it necessary to encourage professionals to promote the participation of the companion during labor and delivery, inserting them and guiding them about the processes.
\end{abstract}

Keywords: Nursing, Humanized childbirth, Fatherhood, Labor obstetric.

\section{RESUMEN}

Objetivo: Comprender la percepción del padre sobre el nacimiento del hijo en una maternidad pública de Rio Grande do Sul. Métodos: Estudio descriptivo y cualitativo, realizado con los padres durante el trabajo de parto y parto de su pareja en un Alojamiento Conjunto, utilizando entrevistas semiestructuradas para gosto y

${ }^{1}$ Hospital São Francisco de Assis, Parobé - RS.

2 Faculdades Integradas de Taquara (FACCAT), Taquara - RS. *E-mail: monique.vargas@faccat.br 
noviembre de 2020. Resultados: Once padres participaron del estudio, con una edad prevalente entre 20-30 años, la mayoría de los cuales tienen educación primaria incompleta, origen de Parobé y estado civil casado. El número de partos por cesárea fue mayor y el $73 \%$ de los partos fueron atendidos. Los hallazgos del estudio propusieron reflexionar y discutir sobre la emoción y felicidad del nacimiento del hijo, la satisfacción con el cuidado brindado por el equipo, la ansiedad y preocupación por el parto, las expectativas sobre el nacimiento, la participación durante el trabajo de parto y el parto y la seguridad al convertirse en padre. Conclusión: Podemos resaltar la importancia y el deseo por parte de los padres de vivir estos momentos de manera activa, siendo necesario incentivar a los profesionales a promover la participación del acompañante en el momento del trabajo de parto y parto, insertándolos y orientándolos sobre los procedimientos.

Palabras clave: Enfermería, Parto humanizado, Paternidad, Trabajo de parto.

\section{INTRODUÇÃO}

$\mathrm{Na}$ contemporaneidade a paternidade não se baseia mais em prover apenas bens materiais, a presença do pai é importante em todo desenvolvimento da criança para amar, educar, cuidar e fortalecer os vínculos de afeto. Desta forma, é papel do profissional de saúde intervir de forma dinâmica buscando estabelecer características desse novo modelo de paternidade na sociedade, sempre dando luz às particularidades de cada homem e buscando conhecê-lo de maneira holística (SANTOS CP, et al., 2018).

Para que o todo o processo gravídico-puerperal transcorra de forma positiva, faz-se necessário o apoio e a participação do pai em todas as fases deste período, desde a concepção ao pós-parto (SANTOS CP, et al., 2018). Conforme a Lei do Acompanhante, Lei Federal no 11.108 de abril de 2005, permite à gestante o direito à acompanhante e que este seja indicado pela mesma, podendo acompanhá-la durante todo o período de trabalho de parto, parto e pós-parto, em todos os serviços de saúde do Sistema Único de Saúde (SUS). Como direito, a gestante ainda pode indicar quem será seu acompanhante. (BRASIL, 2005). Já a Lei 9.263/1996 reconhece a importância do casal no atendimento integral da saúde, nos diversos ciclos de vida, tendo em vista garantir o planejamento familiar (BRASIL, 1996).

Corroborando com a legislação, leva-se em consideração as preferências e expectativas das parturientes no que tange a adaptação do papel de apoio pelos pais, seja no pré, trans e pós-parto. Os pais devem ter participação ativa nesse processo, atuando de forma positiva e autêntica, trazendo assim impactos favoráveis e atenuando a sua confiança e valorização (LEITE DA, et al., 2018).

Para que essa presença paterna possa ocorrer de forma eficaz, é preciso que os profissionais de saúde sensibilizem a sociedade sobre a importância deste acompanhamento e criem estratégias voltadas ao homem de uma forma que o envolva no pré-natal e ao mesmo tempo promova o cuidado à sua saúde. Percebe-se que, por meio da literatura, a presença do pai ainda é pouco discutida, por isso, deve-se propor um maior incentivo à pesquisa por parte dos profissionais da saúde, especialmente pela enfermagem, acerca dessa temática (BONIM SS, et al., 2020).

Diante do exposto, este trabalho objetivou conhecer a percepção do pai frente ao nascimento do filho em uma maternidade pública de um Hospital do Rio Grande do Sul (RS).

\section{MÉTODOS}

Trata-se de um estudo descritivo, com abordagem qualitativa, realizado em um Alojamento Conjunto de um hospital público localizado em um município do Estado do Rio Grande do Sul. A população da pesquisa foi composta por 11 pais que estiveram presentes no trabalho de parto e parto de sua companheira no período da coleta de dados que ocorreu nos meses de agosto a novembro de 2020.

A coleta de dados se deu através de uma entrevista semiestruturada em até 6 horas após o parto e após a assinatura do Termo de Consentimento Livre e Esclarecido (TCLE). A seleção dos participantes para a entrevista deu-se por meio dos seguintes critérios de inclusão: pais que tenham participado do trabalho de 
parto e/ou parto cesárea ou vaginal, e idade maior de 18 anos. E quanto aos critérios de exclusão, foram os seguintes: acompanhantes de gestantes de alto risco, partos prematuros, pais de natimorto e pais que trabalham em centro obstétrico.

Todas as entrevistas foram gravadas em um gravador digital e posteriormente transcritas. Os participantes mantiveram o anonimato preservado e foram identificados como P1, P2, P3 e assim sucessivamente. O término da coleta deu-se quando a saturação dos dados foi atingida.

A análise se baseou na proposta de análise de conteúdo descrita por Minayo MCS (2014) onde se buscou descobrir as unidades de significação que compõem uma comunicação cuja presença ou frequência significou alguma coisa para o objetivo analítico, processo este que se desdobrou em três etapas: pré-análise; exploração do material; e tratamento dos resultados obtidos e interpretação.

Esta pesquisa esteve em conformidade com a resolução 510/16 referente à pesquisa em ciências humanas e sociais onde recebeu aprovação pela Comissão Científica das Faculdades Integradas de Taquara/FACCAT sob número do Certificado de Apresentação para Apreciação Ética (CAAE): 35681020.2.0000.8135 (BRASIL, 2016).

\section{RESULTADOS E DISCUSSÃO}

Participaram da pesquisa 11 pais, com idade mais prevalente entre $20-30$ anos (72\%). O tipo de parto com maior prevalência foi cesárea com (63\%), seguido do parto vaginal (37\%). A procedência dos participantes resultou em (45\%) dos pais de Parobé, seguido de Rolante (27\%), Três Coroas (18\%) e Taquara (10\%), todos municípios do Vale do Paranhana, sendo o hospital da pesquisa referência para o serviço de obstetrícia da região.

O grau de instrução com mais prevalência dos pais foi o ensino fundamental incompleto (45\%), seguido de ensino médio incompleto (18\%), ensino médio completo (18\%), ensino fundamental completo (9\%) e técnico (9\%). A ocupação teve maior prevalência com outros tipos de profissões (64\%), seguido de calçadista (18\%) e desempregado (18\%). O vínculo com a mãe foi mais prevalente pais casados (55\%), moram juntos (27\%), união estável (9\%) e namorando (9\%). O número de partos assistidos foi prevalente, em $72 \%$ sendo o primeiro parto assistido pelos pais, (18\%) nenhum parto, e (10\%) dois.

Por meio dos dados, houve o surgimento de seis categorias temáticas que serão apresentadas e discutidas a seguir.

\section{Emoção e felicidade ao nascimento}

A gestação é um período único e muito esperado na vida das mulheres, que envolve muitas transformações, tanto físicas quanto psicológicas (SILVA MH, et al., 2021). A emotividade, qualidade ou estado de estar emotivo se torna presente nos processos de parto. Segundo Santos CP, et al. (2018), os sentimentos vivenciados pelos pais no momento do nascimento de seus filhos são indescritíveis, trazendo encantamento, felicidade e orgulho ao ver o filho. Durante as entrevistas notou-se estes sentimentos pelas seguintes falas:

"[..] foi uma alegria muito grande né, é o filho da gente né, esperamos bastante tempo por isso, na hora assusta né" (P2).

"[...] ah, foi muito incrivel, fiquei muito feliz, a vida parece ter sentido, nasce um filho tua vida começa a dar um giro" (P9).

"[...] eu fiquei muito alegre em saber que ele tava bem e vivo" (P5).

As falas demonstram que para os pais, participar do nascimento é uma experiência de felicidade, que gera um turbilhão de sentimentos, destacando a alegria. A vivência do processo de nascimento pelos pais gera sentimentos difíceis de serem traduzidos, trazendo expectativas do homem como pai, gerando preocupação, insegurança e ansiedade. Em alguns pais o sentimento de paternidade só é aflorado depois do nascimento do filho, o que antes era sentido como algo abstrato (SANTOS SS, et al., 2021). Pôde-se notar a presença destes termos nas falas a seguir: 
"[..] meio indescritível conseguir gerar uma vida assim" (P5).

"[...] emoção alegria, muita alegria, no começo é apavorante mas depois é emotivo e legal" (P5).

É notório a alegria vivenciada pelos pais através dos relatos. Por outro lado, como descrito por Leite DA, et al. (2018), ao acompanhar o nascimento os pais também se sentem com medo e preocupação por acharem o parto um momento doloroso e sofrido para a mulher, ressaltando a sua coragem e força nesse processo. É nesta etapa, trabalho de parto e parto, que o pai se sente, de certa forma útil em ajudar a companheira (SILVA ARR, 2019). Este é um dado que se assemelha ao encontrado no presente estudo, como demonstrado a seguir:

"[...] ao mesmo tempo faz a gente pensar assim como as mulheres sofrem né. Eu falei para ela, amor eu tenho que te dar os parabéns mais uma vez, não por ter me dado um filho, mas também por ver o que uma mulher passa né, imagina é muito..., um homem reconhecer isso é bem difícil" (P9).

Intimidade com a mulher, admiração pela força, sensação de orgulho e satisfação com a chegada do bebê são sensações positivas vivenciadas pelo acompanhante. Ainda como ponto positivo entende-se ser a inserção do homem no nascimento, pois lhe dá um novo delineamento sobre o seu papel (LEITE DA, et al., 2018).

\section{Satisfação com o atendimento da equipe}

Os profissionais de saúde devem sempre valorizar a participação do pai/parceiro evitando-se tratá-lo como visita, pois além da liberdade de acesso à sua parceira e ao seu filho no ambiente, ações simples como o suporte à sua parceira, o clampeamento do cordão umbilical e o primeiro banho do Recém Nascido (RN), dão a ele um protagonismo nesta família (BRASIL, 2016).

Durante todo o processo de espera da chegada do filho, é comum que os pais busquem acompanhar suas parceiras e auxiliar a equipe (LEITE DA, et al., 2018). Dentre estes processos, os participantes avaliaram o atendimento da equipe prestado a si e a sua companheira. Dentro disso, grande parte refere ser bem atendido. O que se pode notar pelos depoimentos a seguir:

"[...] foi, a gente foi muito bem atendidos, a maior preocupação era na hora do parto né, a gente foi muito bem atendido, as enfermeiras muito atenciosas né, muito queridas, atendeu a gente muito bem" (P1).

\section{"[...] a gente foi tudo bem atendido" (P2).}

O papel dos profissionais de saúde é crucial para minimizar os sentimentos negativos vivenciados pelo casal e ajudá-los a viver a experiência do nascimento do filho na sua plenitude (SILVA ARR, 2019). Isso é relatado nas seguintes falas:

"[...] a gente foi muito bem atendido até o pessoal do bloco cirúrgico, todo mundo conversando, falando o que tava acontecendo na hora sabe, tudo bem tranquilo, ninguém escondendo nada de ninguém" (P5).

"[...] tiveram a responsabilidade" (P7).

As orientações não devem se iniciar no trabalho de parto e sim durante todo o pré-natal. Essas informações são parte integrante na gravidez, realizadas através do incentivo à ida nas consultas pré-natais, ida às ecografias, presença nas aulas de preparação para o parto e ainda a importância sobre a comunicação e o contato com o feto (SILVA ARR, 2019).

\section{Ansiedade e preocupação com o parto}

Os participantes desta pesquisa quando questionados sobre como se sentiram no processo de parto, relataram que estavam ansiosos, preocupados e que era um momento de expectativa. Dados estes que vão ao encontro do que já vem sendo exposto na literatura por Silva ARR (2019), onde refere que as principais 
emoções sentidas pelos pais durante o parto são ansiedade, felicidade e nervosismo e que após o nascimento os sentimentos se voltam à alívio, felicidade e proteção. Nota-se estes sentimentos nos depoimentos a seguir:

"[...] ansioso, preocupado" (P1).

"[...] momento de expectativa, então tu fica apreensivo né" (P5).

"[...] tava ansioso só esperando a hora da nenê nascer" (P9).

"[...] ah a gente fica sofrendo junto né, na primeira vez não sabe muito o que fazer" (P2).

O desconhecimento, a desinformação, a dificuldade de lidar com as emoções durante o trabalho de parto e parto, podem levar a presença passiva do pai como acompanhante. Nesta perspectiva, trocar conhecimentos, experiências e esclarecer dúvidas quanto à dinâmica de parto com a equipe de saúde é fundamental para estimular uma postura mais ativa do pai, evitando fantasia e ansiedade pelo casal (OLIVEIRA PC, et al., 2021).

\section{Expectativas com o nascimento}

A participação do pai serve também para desmistificar os sentimentos de apreensão e nervosismo do momento e também trazer alegria e felicidade ao ver o filho nascendo (MENDONÇA FAC, et al., 2018). Diante as expectativas frente ao nascimento do filho, os seguintes depoimentos foram expostos:

"[...] todo mundo fala que as dor são normal, mas só estando na hora vendo a quantia que ela sofre pra gente ter uma ideia mesmo" (P2).

"[...] eu acho que foi mais complicado do que na hora do parto, porque ela tava sofrendo bastante, mas eu vim preparado, eu já imaginava que ela ia ganhar e eu tava junto para apoiar ela" (P4).

"[...] ajudar assim, sempre né dar força que é um momento bom e delicado para a mãe eu acho que seria isso ta junto ali dando aquela força aquele apoio necessário acho que era isso" (P6).

"[...] eu sabia que a dor era só aquele momento, né, até nascer depois a gente ia ter alegria já, já ia tá feliz já" (P9).

Percebe-se que as expectativas dos pais se voltam muito a ter consciência da dor do trabalho de parto e parto, além da esperança de que esta dor passe após o nascimento do filho, o que se remete fortemente aos medos e anseios envolta deste momento.

É comum que todo pai tenha esses sentimentos e para isso é indispensável um olhar especial e empático pelos profissionais de saúde. Este olhar auxilia o pai a compreender quaisquer sejam suas colocações relacionadas ao que está sentindo, dentre tantas outras particularidades que constituem e idealizam o "ser pai" (SANTOS SP, et al., 2018).

Nour GFA (2018) mostra que muitos pais acabam recomendando a outros pais assistirem o parto dos seus filhos, por acharem o momento especial e único e que muda a consciência de um homem, sendo este dado evidenciado na seguinte fala:

"[...] acho que tinha que ser obrigatório assistir porque é uma coisa que muda a consciência do homem com certeza" (P9).

\section{Participação durante o trabalho de parto e parto}

A participação do pai durante o período de trabalho de parto e nascimento vai muito além do cumprimento de regras, normas e leis. A informação adequada sobre seus direitos enquanto participante ativo desse processo deve ser disseminada e encorajada. Isso favorece o desenvolvimento de vínculos importantes na constituição do papel de ser pai, do desempenho da mulher como mãe e do crescimento e desenvolvimento adequado da criança (OLIVEIRA PC, et al., 2021). Desta forma, é essencial ressaltar constantemente o direito de se ter acompanhante neste momento, o que é respaldado por lei. 
A presença do pai no parto e nascimento pode também caracterizar um momento de "despertar para a paternidade", pois é aí que o primeiro contato com o filho ocorre, e então, o que era apenas imaginação durante a gestação torna-se realidade (SANTOS CP, et al., 2018).

Nos depoimentos a seguir nota-se a importância que os pais dão em se estar presente e apoiar as escolhas da companheira:

"[...] sim, desde a partir do momento que ela botou na cabeça que ia fazer cesárea até agora, (estive) sempre com ela [...] ajudar assim, sempre né dar força que é um momento bom e delicado para a mãe" (P5).

Em conformidade, Jardim DMB e Penna CMM (2012) afirmam que no dia a dia os acompanhantes, neste caso os pais, suportam a dor sentida por suas mulheres como uma forma de apoiá-las. Estes se esforçam muito para minimizar essa dor por meio de palavras de apoio e força, gestos de carinho, massagens e toques, o que se percebeu pelos seguintes comentários:

“[...] pra mim me colocar no lugar dela também, pela empatia né [...] peguei a cabeça dela e encostei no meu peito e falei amor olha pra mim" (P9).

Frente a essa situação, percebeu-se neste presente estudo que os participantes possuem vontade de conhecer o contexto de parto, porém, segundo Antunes JT, et al. (2014), essa curiosidade sugere que o parto está, de certa forma, presente no imaginário masculino, o que mobiliza o desejo de conhecer e participar desse evento.

Aos participantes foi questionado se houve a participação no momento do trabalho e parto. Dentro disso nos deparamos com a seguinte fala:

"[...] atenderam bem a gente, aí eu fui no quarto com ela mas não pude assistir o parto [...] o médico não deixou. Daí depois ele até ia deixar, mas tava com pressa, ele fez acho que 3 cesáreas eu acho que em uma hora e meia eu acho [...] é muito difícil eles deixarem né, só quando o hospital tem poucas mães pra ganhar nenê né, se não é difícil" (P1).

Este dado demonstra a violação do direito da gestante em estar acompanhada durante o parto. Já no próximo depoimento evidenciou-se o desejo na não participação deste momento:

\section{"[...] do parto lá dentro eu não entrei [...] bah, eu nem tava muito afim de entrar mesmo" (P2)}

Santos CP, et al. (2018) já vem comentando em seus estudos quanto à essa perspectiva. Relata que muitos são os aspectos responsáveis por desencadear o absentismo dos pais no parto, como atraso, falta de estímulo, medo ou até por vontade da mulher. Estas situações podem e devem ser evitadas por meio da discussão anterior sobre estes assuntos, explanando que o evento do nascimento é único e solene, que a presença é favorável para a mulher, para o bebê e para si mesmo, consolidando laços familiares e firmando o papel de pai presente.

É preciso que além da mulher, o homem também seja visto como protagonista do nascimento, tornando o parto humanizado, isto se faz necessário pois entende-se que a gravidez e parto representam um momento especial na vida do casal e não só da mulher (SANTOS CP, et al., 2018).

Para que a participação do pai nos cuidados durante a gestação, parto e pós-parto seja efetiva, é preciso que as leis do nosso país sejam modificadas, em que o pai consiga se ausentar do trabalho sem nenhum prejuízo adicional proporcionando assim participação nesse processo (HENZ GS, et al., 2017).

\section{Segurança de ser pai}

A maioria dos pais deste estudo não se sente preparado para desenvolver o papel de paternidade, mesmo sendo a sua segunda experiência. Então, é possível concluir que este tema deveria ser trabalhado desde o pré-natal, porém sabe-se que são poucos os pais que possuem a oportunidade de participar deste processo. Quando questionados sobre a participação no pré-natal, encontrou-se os seguintes depoimentos: 


\section{“[...] não muito porque eu trabalho fora, os horários não permitiam" (P3). \\ “[...] não, não, porque não podia entrar" (P8)}

Alguns pais deste estudo dizem que ao participar do pré-natal se sentem mais bem preparados para assumir a figura de pai, já os que não participaram relataram não estar preparados. Relatos de pais referente a gestação reforçam que o cuidado com a gestante é intensificado neste período, como forma de atingir o bebê positivamente (FITERMAN H e MOREIRA LVC, 2018).

Em especial, aos pais "de primeira viagem", é importante atentar para fatores que influenciam na saúde mental e no desempenho de cada um ao assumir esse papel, que podem impactar na transição para a paternidade: formação da identidade de paternidade; desafios conflitantes desse novo papel; sentimentos negativos e medos relacionado a ela (BALDWIN S, et al., 2018).

O fato do homem estar passando para uma nova fase de sua vida pode explicar a ansiedade sentida, visto que suas atribuições e responsabilidades consequentemente serão maiores com a chegada do filho, além disso o decorrer natural da gestação já vem a acrescer esse sentimento. Expressar a felicidade como sentimento primário à ansiedade é, segundo, uma hierarquização de sentimentos que pode impulsionar o homem a exercer a paternidade de forma mais acolhedora, criando vínculo com o filho e em contrapartida transmitindo tranquilidade e conforto à companheira (SANTOS CP, et al., 2018).

As ações de saúde voltadas para o envolvimento dos pais no processo do nascer, bem como na saúde materna e fetal, devem ser planejadas com afinco, para que a relação do casal seja preservada e que a mitigação de fatores fragilizados desse período favoreça à tomada de decisão e à comunicação no núcleo familiar (TOKHI M, et al., 2018).

O envolvimento dos parceiros junto às mulheres durante o ciclo gravídico-puerperal através de grupos de gestantes ou com orientações durante as consultas de pré-natal, faz com que fortaleça o vínculo com a mulher e o bebê, diminua a ansiedade e o prepare para vivenciar o momento parto e puerpério com maior conhecimento, ajudando assim toda a família nesse novo tempo (RAUBER CS, et al., 2021).

\section{CONCLUSÃO}

Os pais interpretam o trabalho de parto e parto como um momento de sentimentos intensos, muitas vezes difíceis de serem traduzidos. Sentir o momento como algo incrível, único e responsável por dar sentido à vida, foram citações que ocorreram em todos os relatos, o que revela a importância do momento para a vida do pai. No entanto, mesmo possuindo desejo genuíno em se tornar pai, a participação no parto em si não garante este preparo, nem tão pouco minimiza inseguranças. Logo, se faz necessário por parte dos profissionais de saúde, principalmente o enfermeiro, que seja promovido a corresponsabilização dos pais frente aos cuidados, além da participação durante a gestação, trabalho de parto e parto, e de todo o desenvolvimento da criança. Desta forma, este estudo contribui com reflexões pertinentes que tangenciam avanços na elucidação de políticas públicas voltadas à participação do homem.

\section{REFERÊNCIAS}

1. ANTUNES JT, et al. Presença paterna na sala de parto: expectativas, sentimentos e significados durante o nascimento, Santa Maria. Revista de Enfermagem da UFSM, 2014; 4(3): 536-545.

2. BALDWIN S, et al. Mental health and wellbeing during the transition to fatherhood: a systematic review of first time fathers' experiences. JBI database of systematic reviews and implementation reports, 2018; 16(11): 2118-2191.

3. BONIM SS. de S et al. A importância da participação do pai no acompanhamento do pré-natal. Rev. Saberes, Rolim de Moura, 2020; 13(1).

4. BRASIL. Presidência da República. Lei no 11.108, de 7 de abril de 2005 . Disponível em: http://www.planalto.gov.br/ccivil_03/_ato2004-2006/2005/lei/l11108.htm. Acessado em: 02 de agosto de 2021.

5. BRASIL. Presidência da República. Lei no 9.263 , de 12 de janeiro de 1996 . Disponível em: http://www.planalto.gov.br/ccivil_03/leis/l9263.htm\#: :text=LEl\%20N\%C2\%BA\%209.263\%2C\%20DE\%2012\%20DE \%20JANEIRO\%20DE\%201996.\&text=Regula\%200\%20\%C2\%A7\%207\%C2\%BA\%20do,penalidades\%20e\%20d\%C $3 \%$ A1\%20outras\%20provid\%C3\%AAncias.\&text=DO\%20PLANEJAMENTO\%2OFAMILIAR-

,Art.,observado\%200\%20disposto\%20nesta\%20Lei. Acessado em: em 02 de agosto de 2021. 
6. BRASIL. Resolução $n^{\circ} 510$, de 07 de abril de 2016 . Disponível em: http://conselho.saude.gov.br/resolucoes/2016/Reso510.pdf. Acessado em: 04 de junho de 2020.

7. FITERMAN H, MOREIRA LVC. O pai na gestação, no parto e aos três meses de vida do primeiro filho. Polis, Revista Latinoamericana, 2018; 15(50): 47-68.

8. HENZ GS, et al. A Inclusão paterna durante o pré-natal. Revista Enfermagem Atenção Saúde. 2017; 6(1): 52-66.

9. JARDIM DMB, PENNA CMM. Pai-acompanhante e sua compreensão sobre o processo de nascimento do filho. Revista Mineira de Enfermagem, 2012; 16(3): 373- 381.

10. LEITE DA. Vivências do pai no pré natal, pré parto e parturição no século XXI. Trabalho de Conclusão de Curso (Graduação em Enfermagem) - Faculdade de Medicina. Universidade Federal de Uberlândia, Uberlândia, 2018; 37p.

11. MINAYO MCS. O desafio do conhecimento: pesquisa qualitativa em saúde. 14 ed. São Paulo: Hucitec, 2014.

12. MENDONÇA FAC. Barreiras relatadas pelo pai acerca da participação do parto no

13. Nordeste brasileiro. Investigação Qualitativa em Saúde, 2017; 2.

14. NOUR GFA. Cartilha educativa para promoção do envolvimento do pai no parto e nascimento: construção e validação. Dissertação (Mestrado em Saúde da Família) - Pós Graduação em Saúde da Família. Universidade Federal do Ceará, Sobral, 2018; 137p.

15. OLIVEIRA PC, et al. Os benefícios da presença do pai no trabalho de parto e parto. Curitiba. Brazilian Journalof Development, 2021; 7(2):18142-18159.

16. RAUBER CS, et al. Percepções de mulheres sobre a participação paterna em grupos de gestantes. Journal Health NPEPS, 2021; 6(1):272-288.

17. SANTOS CP, et al. Percepção do pai sobre os reflexos de sua presença desde a concepção ao pós-parto imediato para o casal e recém-nascido. Revista da Jornada da Pós Graduação e Pesquisa- Congrega, 2018; 5(2):55-68.

18. SANTOS SS, et al. A construção da paternidade ao nascimento do filho a termo e saudável. Revista Família, Ciclos de vida e Saúde no Contexto Social, 2021; 9(2):767-778.

19. SILVA, ARR. O envolvimento do Pai durante a gravidez, trabalho de parto e parto: Sentimentos percecionados durante e após o nascimento. 2019. Trabalho (Licenciatura em Enfermagem) - Escola Superior de Saúde Porto, Universidade Fernando Pessoa, 2019.

20. SILVA MH, et al. Expectativas e conhecimentos das gestantes sobre o parto normal: revisão integrativa. Centro Universitário de PatosCurso de Medicina, 2021; 6: 129-139.

21. TOKHI M, et al. Involving men to improve maternal and newborn health: A systematic review of the effectiveness of interventions, PloS one Collection, 2018; 13(1): e0191620. 